\title{
Chloride distribution in the CA1 region of newborn and adult hippocampus by light microscopic histochemistry
}

\begin{abstract}
GABA, the main inhibitory neurotransmitter in the central nervous system, exerts its effect by rendering the postsynaptic $\mathrm{GABA}_{\mathrm{A}}$ receptors permeable to chloride ions. Thus, depolarizing or excitatory effects of GABA, experienced in early postnatal life or in certain regions and/or conditions of the adult brain, is thought to be associated with a reversed transmembrane chloride gradient. However, there is only limited direct information about the correlation of the actual excitatory versus inhibitory effects of GABA and the local chloride distribution. Precipitation of chloride with silver is a potential way to immobilize and visualize chloride ions in biological tissue. We examined the applicability of light microscopic histochemistry, based on trapping tissue chloride with silver ions during freeze-substitution or aldehyde fixation, to visualize the chloride distribution in hippocampal slices. The freeze-substitution procedure yielded better chloride retention while with aldehyde fixation tissue preservation was more appropriate. Both methods were qualitative only, had limited applicability to the superficial $20-30 \mu \mathrm{m}$ of slices, but were able to demonstrate a reduced extracellular-to-intracellular chloride gradient in the CA1 pyramidal neurons of the newborn hippocampus as compared to adult animals. In the 4-aminopyridine model of epilepsy, redistribution of chloride from extracellular to intracellular space could also be demonstrated.
\end{abstract}

\section{Siklós (}

Institute of Biophysics, Biological Research Center,

6701 Szeged, P.O. Box 521, Hungary

e-mail: siklos@nucleus.szbk.u-szeged.hu

Tel.: +36-62-432080170, Fax: +36-62-433133

\section{B. Barna}

Department of Comparative Physiology,

József Attila University of Sciences, Szeged, Középfasor 52, 6726, Hungary

\section{U. Kuhnt}

Department of Neurobiology,

Max-Planck-Institute of Biophysical Chemistry, Göttingen, Am Fassberg 11, 37077, Germany
Keywords GABA · Excitatory · Inhibitory ·

Chloride distribution $\cdot$ Histochemistry

\section{Introduction}

A fragile balance between excitation and inhibition, underlying the normal functioning of the central nervous system, largely depends on the adjustment of the inhibitory function: small changes in the inhibition can alter neuronal excitability and lead to malfunctions. Particularly, any decrease in GABAergic inhibition, constituting $20-30 \%$ of synapses (Bloom and Iversen 1971), can lead to neuronal hyperexcitability and seizures (Sloviter 1987; Perreault and Avoli 1991; Mody et al. 1992). Indeed, epileptic discharges can be induced experimentally by compromising GABAergic inhibition (Thompson 1989; Horton 1991), but also by enhancing synaptic excitation in low $\mathrm{Mg}^{2+}$ medium (Anderson et al. 1986) or with aminopyridine derivatives (Szente and Baranyi 1987). Epileptiform activity based on synchronous GABAergic depolarizations possibly associated with action potentials have also been reported (Avoli et al. 1996). Since epilepsy is one of the most common neurologic disorders, numerous studies are aimed to characterize the ionic/molecular mechanisms of GABAergic inhibition and the differential effect of GABA on its neuronal targets.

GABA, once released from nerve terminals, exerts an inhibitory action by binding to its receptors postsynaptically (Mody et al. 1994) and presynaptically (Zhang and Jackson 1993), as well. Pharmacologically, two major groups of GABA receptors can be distinguished. $\mathrm{GABA}_{\mathrm{A}}$ receptors are classically defined by their sensitivity to the agonist muscimol and the antagonist bicuculline (Macdonald and Olsen 1994). GABA ${ }_{B}$ receptors can bind the lipophilic GABA analogue baclofen (which depresses neuronal firing) or can be antagonized by phaclofen (Krnjevic 1991). GABA receptors insensitive to both bicuculline and baclofen were termed $\mathrm{GABA}_{\mathrm{C}}$ receptors (Thompson 1994). The $\mathrm{GABA}_{\mathrm{A}}$ receptors are 
members of the ligand-gated ion-channel superfamily which are assembled from the currently known GABA $_{A}$ receptor subunits in a pentamer configuration to form a functional $\mathrm{Cl}^{-}$channel (Mody et al. 1994). The actual subunit composition can influence the channel conductance state, kinetics, and sensitivity to pharmacological modulators of $\mathrm{GABA}_{\mathrm{A}}$ receptor function (Sigel et al. 1990; Verdoorn et al. 1990; Mehta and Ticku 1999). Since all $\mathrm{GABA}_{\mathrm{A}}$ receptors are permeable to $\mathrm{Cl}^{-}$, their activation results in large increases in membrane conductance and strong shunting of excitatory currents (Bormann et al. 1987). However, activation of $\mathrm{GABA}_{\mathrm{A}}$ receptors can lead postsynaptically either to hyperpolarization or depolarization depending on the relationship between the $\mathrm{Cl}^{-}$reversal potential $\left(\mathrm{E}_{\mathrm{Cl}}\right)$ and the resting membrane potential $\left(\mathrm{E}_{\mathrm{M}}\right)$.

Observations revealing that in most neurons $\mathrm{E}_{\mathrm{Cl}}$ is consistently either larger or smaller than $E_{M}$ were summarized in a general statement that $\mathrm{Cl}^{-}$is not passively distributed across the membranes (Alvarez-Leefmans 1990). The major mechanisms supporting the $\mathrm{E}_{\mathrm{M}}-\mathrm{E}_{\mathrm{Cl}}$ driving force for $\mathrm{Cl}^{-}$are the $\mathrm{K}^{+}, \mathrm{Cl}^{-}$and the $\mathrm{K}^{+}, \mathrm{Na}^{+}$, $\mathrm{Cl}^{-}$cotransport systems as well as the $\mathrm{Na}^{+}$-coupled $\mathrm{Cl}^{-} / \mathrm{HCO}_{3}$ exchanger (Cala 1990). According to our present knowledge, the local magnitude of the actively maintained $\mathrm{Cl}^{-}$transmembrane gradient cannot be calculated, however, besides its usually inhibitory action, excitatory GABA effects could also be demonstrated. Thus, in tissue culture from superior cervical ganglion the ability of GABA to evoke action potentials was already demonstrated in 1976 (Obata 1976). More recent experiments revealed that GABA - specifically via $\mathrm{GABA}_{\mathrm{A}}$ receptors - can evoke excitatory potentials in the hippocampus: the GABAergic population of hilar neurons has been shown to synchronize with each other by reciprocal excitation, in order to deliver a synchronized inhibition to the CA3 pyramidal cells (Michelson and Wong 1991). It is interesting to relate this result to findings of Cherubini and co-workers, who described that GABA exerts an excitatory effect in neonatal CA3 hippocampal neurons, detected as giant depolarizing potentials, which are supposed to be $\mathrm{Cl}^{-}$dependent (BenAri et al. 1989; Cherubini et al. 1990). They concluded that GABA is an excitatory transmitter in the CNS during the early postnatal period, and exhibits the inhibitory features only after the 8th day from birth in rats (Cherubini et al. 1991). According to their explanation, the GABA depolarization in neonatal neurons might be due to a modified $\mathrm{Cl}^{-}$gradient across the cell membrane and may be neither the consequence of the endogenous $\mathrm{Zn}^{2+}$ effect, nor of rewiring of existing neuronal connections (Ben-Ari and Cherubini 1991). This view gained further support from recent electrophysiological and in situ hybridization studies. The introduction of gramicidin perforated patch electrodes into the studies of GABAmediated responses provided the possibility to correlate depolarizing/hyperpolarizing effects of GABA with the true intracellular chloride concentration (Kyrozis and Reichling 1995). Such studies demonstrated a chloride- dependent shift from depolarizing to hyperpolarizing responses to GABA with maturation (Owens et al. 1996), which fits well to the recent demonstration of the developmental changes in the expression of the $\mathrm{K}^{+} / \mathrm{Cl}^{-}$ cotransporter (Rivera et al. 1999).

The ultimate aim of direct visualization of intracellular chloride concentration in order to correlate it with different functional states of individual cells or neuronal networks lead to the development of $\mathrm{Cl}^{-}$-sensitive fluorescent dyes such as SPQ or MQAE (Verkman 1990; Inoue et al. 1991; Hara et al. 1992). However, due to the still unresolved problems, such as fast leakage of the indicators from the cells, the lack of ratiometric measurements, and the low spatial resolution of the method, the interpretation of the results obtained with the available dyes is still difficult.

In the present paper, as an alternative approach, we attempt to apply and test the capacity of the histochemical methods, based on silver precipitation to fix and visualize tissue chloride, in obtaining direct information about the transmembrane chloride distribution of neurons in hippocampal slices. We did not expect to be able to follow changes characteristic for fast transneuronal signaling since neither the physical (freeze-substitution) nor the chemical (aldehyde) fixation method of biological tissue works on a time scale of the millisecond range. Instead, demonstration of different steady-state distributions or documentation of changes during long-lasting physiological alterations was intended. For this purpose, on the basis of literature data, the comparison of chloride distribution in newborn and adult hippocampus seemed to be appropriate. In addition, the method was applied to compare the chloride distribution in normal adult and 4-aminopyridinetreated hippocampus.

\section{Materials and methods}

Hippocampal slice preparation

Hippocampal slices were prepared either from newborn (day 5-6 postnatal) or adult Wistar rats. Animals were decapitated, their brains were removed and placed in ice-cold oxygenated bathing medium, and then both hippocampi were removed. From the hippocampi, 400- $\mu \mathrm{m}$-thick transverse slices were cut on a "Rotor Slicer" (D.S.K., Dosaka, Japan) and then slices were kept submerged at $29^{\circ} \mathrm{C}$ in a bathing medium containing $124 \mathrm{mM} \mathrm{NaCl}$ (Mallinckrodt Baker, Deventer, The Netherlands), $5 \mathrm{mM} \mathrm{KCl}$ (Merck, Darmstadt, Germany), $1.25 \mathrm{mM} \mathrm{NaH} \mathrm{PO}_{4}$ (Merck), $2.0 \mathrm{mM} \mathrm{MgSO}{ }_{4}$ (Sigma-Aldrich, Steinheim, Germany), $1.0 \mathrm{mM}$ $\mathrm{CaCl}_{2}$ (Merck), $26 \mathrm{mM} \mathrm{NaHCO}$ (Merck), and $10 \mathrm{mM}$ glucose (Sigma-Aldrich) saturated with $\mathrm{O}_{2} / \mathrm{CO}_{2}(95 \% / 5 \%)$, giving a $\mathrm{pH}$ of 7.4. These experiments were performed in accordance with institutional guidelines for animal experiments and with governmental laws for animal protection.

Electrophysiologic control of normal and 4-aminopyridine-treated slices

All the slices from the dissected hippocampi were maintained in the storage chamber regularly for $60 \mathrm{~min}$. After this period, randomly selected slices, at least one from each hippocampus, were transferred to the recording chamber to check their functional 
intactness. In the recording chamber ( $0.8 \mathrm{ml}$ volumetric capacity) slices were kept at $32^{\circ} \mathrm{C}$ and superfused at a rate of $10 \mathrm{ml} / \mathrm{h}$ with standard medium (but $2 \mathrm{mM} \mathrm{Ca}{ }^{++}$), gassed with $\mathrm{O}_{2} / \mathrm{CO}_{2}$. The functional intactness of slices was controlled by recording evoked extracellular field potentials with glass recording electrodes $(3 \mathrm{M}$ $\mathrm{NaCl}, 5-10 \mathrm{M} \Omega$ ) for $30 \mathrm{~min}$ in the stratum pyramidale and stratum radiatum of the CA1 region. Recordings were monitored on a PM 3350 digital oscilloscope (Philips, Eindhoven, The Netherlands). Unipolar stimulating electrodes (tungsten in glass, tip diameter below $50 \mu \mathrm{m}$ ) were placed in the stratum radiatum at the border of CA3 and CA2 regions. Stimuli (duration of $40 \mu \mathrm{s}$ ) were given at $0.1 \mathrm{~Hz}$, and the intensity was adjusted such that a population spike could be recorded at the pyramidal cell layer.

Slices aimed to be used for histochemical characterization of the chloride distribution during epileptiform activity were also transferred to the recording chamber after a 60-min recovery period following slice preparation. Epileptiform activity was induced by application of $100 \mu \mathrm{M}$ 4-aminopyridine (Sigma-Aldrich) into the superfusion medium. Epileptiform events were evoked by single pulse stimulation of the pyramidal cell layer in area CA3 or the Schaffer collaterals in area CA3/CA2, and monitored for $30 \mathrm{~min}$ by using the pCLAMP-8 program of Axon Instruments (Foster City, Calif., USA). Spontaneous epileptiform activity was seen in all treated slices, which were then fixed according to the freezesubstitution technique.

\section{Chloride trapping during freeze-substitution}

Untreated slices from neonatal or adult rats and slices exhibiting epileptiform activity obtained from adult animals were used for freeze-substitution. Under oxygenated standard medium, with the aid of a glass pipette, slices were first gently sandwiched between two large-holed nylon sieves spaced $400 \mu \mathrm{m}$ apart and then the sieves were locked together. The enclosed slices were removed from the medium using plastic forceps to grab the rim of the sieves and the excess fluid was gently blotted with tissue paper. Finally, the slices were quenched in isopentane (Sigma-Aldrich) cooled with liquid nitrogen to its melting point, quickly transferred into liquid nitrogen, and kept submerged (regularly not longer than for 5-10 min) until processed further. Subsequently, slices were freeze-substituted at $-40^{\circ} \mathrm{C}$ in a $95 \%$ acetone (Mallinckrodt Baker) solution saturated with silver nitrate (Merck; $1.9 \%$ ) for 3 days, which was followed by a wash in $1 \%$ nitric acid (Mallinckrodt Baker) in 95\% acetone for $2 \mathrm{~h}\left(-40^{\circ} \mathrm{C}\right)$ to remove silver salts other than chloride (Van Harreveld 1966). Thereafter, slices were osmicated for $2 \mathrm{~h}$ [2\% osmic acid (SigmaAldrich) dissolved in $95 \%$ acetone, $-40^{\circ} \mathrm{C}$ ], dehydrated in three steps in $100 \%$ acetone $\left(-40^{\circ} \mathrm{C} 1 \mathrm{~h}, 4^{\circ} \mathrm{C} 1 \mathrm{~h}\right.$, room temperature $1 \mathrm{~h}$ ), and under acetone were removed from the bracketing sieves. Finally, samples were processed through propylene oxide (Serva, Heidelberg, Germany) at room temperature (three changes, 5 min each) and embedded in Spurr's resin (Plano, Wetzlar, Germany; Spurr 1969).

\section{Chloride trapping during aldehyde fixation}

Untreated slices from neonatal and adult rats were selected for combined chloride trapping and aldehyde fixation. Slices were removed from the oxygenated medium using a glass pipette, gently mounted on a spatula, and the excess fluid was quickly removed from the intimate vicinity of the slices using thin strips of tissue paper. Slices were then put into the unbuffered fixative $[2.5 \%$ $\mathrm{AgNO}_{3}, 2.5 \%$ glutaraldehyde (Polysciences, Warrington, Pa., USA), $4^{\circ} \mathrm{C}, \mathrm{pH}$ ca 5-5.5] and kept in the same fixative for $24 \mathrm{~h}$ at $4^{\circ} \mathrm{C}$ in total darkness. After fixation, slices were rinsed in distilled water, then washed in $1 \% \mathrm{HNO}_{3}$ (in distilled water) for $2 \mathrm{~h}$ at $4^{\circ} \mathrm{C}$, rinsed again in distilled water, and osmicated $\left(1 \% \mathrm{OsO}_{4}\right.$ in distilled water) for $2 \mathrm{~h}$ at $4^{\circ} \mathrm{C}$ followed by a rinse in distilled water. Finally, slices were dehydrated in a graded series of ethanol (Mallinckrodt Baker), processed through propylene oxide, and embedded in Spurr's resin.
Light microscopic visualization of silver chloride precipitates

After polymerization, blocks were exposed to high intensity light for $1 \mathrm{~h}$ to reduce silver chloride to yellow-brown subhalides and then trimmed to the CA1 region. From the blocks semithin (1.0 $\mu \mathrm{m}$ thick) sections were cut on a Reichert Om-U2 ultramicrotome (Reichert, Vienna, Austria). These sections, regardless of being obtained from the freeze-substituted or the aldehyde-fixed material, were further treated in the same way. Sections were first placed on drops of distilled water on glass slides then dried at $56^{\circ} \mathrm{C}$ for $10 \mathrm{~min}$, to ensure a smooth surface and good adherence. Well-attached, 1.0- $\mu$ m-thick sections were etched for $2 \mathrm{~min}$ in $5 \%$ $\mathrm{NaOH}$ (Mallinckrodt Baker) dissolved in a 1:1 mixture of absolute ethanol and propylene oxide at room temperature (Maxwell 1978), and rinsed in ethanol followed by distilled water. The exposed tissue of sections was then treated with a freshly prepared silver intensification solution made either from the kit of Janssen (IntenSE M; Olen, Belgium) or Aurion (R-GENT; Wageningen, The Netherlands) by following the appropriate data sheet instructions. Finally, sections were counterstained according to Richardson (1960), coverslipped with DPX mounting medium (Electron Microscopy Sciences, Fort Washington, Pa., USA), and examined in a Zeiss Photomicroscope II light microscope (Oberkochen, Germany). Prints were made with an Epson Stylus Photo 700 color printer using the digital imaging system attached to the microscope, consisting of a Sony DXC 950P CCD camera, Flashpoint 128 frame grabber, and Photoshop 5.0 software (Adobe Systems, San Jose, Calif., USA) running on a Pentium MMX PC at $166 \mathrm{MHz}$. Semiquantitative assessment of the density of precipitates over the perikaryonal region and proximal dendritic segments of CA1 pyramidal cells was performed using Image Pro Plus 4.0 software (Media Cybernetics, Silver Spring, Md., USA). First, the boundaries of the regions to be analyzed were introduced manually using the pointing device of the system and then the silvercontaining granules were segmented by subtracting the background, based on color and contrast differences. Finally, the proportion of the perikaryonal area covered by the precipitates was determined by the area measurement function of the program. For this analysis, from each group to be compared, we selected five or six neurons with their somata and proximal dendritic regions equally recognizable.

\section{Specificity control of chloride-trapping procedures}

Ultrathin sections (with 25-35 nm thickness) were cut from blocks obtained both with the freeze-substitution method and the aldehyde fixation technique, and were mounted on 700-mesh uncoated copper grids (Plano, Wetzlar, Germany). Samples were used to analyze the co-distribution of silver and chloride and the composition of the histochemical reaction products, without any heavy metal staining, in an electron-filtering electron microscope (Zeiss CEM 902) equipped with a high sensitivity SIT-DAGE camera (MTI-66) and a digital TV-image analysis system (IBAS 2.0, Kontron, Munich, Germany).

\section{Electron spectroscopic imaging (ESI)}

This technique is an appropriate method to investigate the twodimensional distribution of selected elements of the tissue on the electron microscopic scale (Bauer 1988). For structural imaging and to screen the sections for precipitates the energy loss value of $250 \mathrm{eV}$ (carbon edge image) was selected. To determine the distribution of silver and chloride in the tissue, images were recorded at several randomly selected locations. Structural images were first recorded at the carbon absorption edge and then image pairs were collected at the specific elemental absorption edges (for chloride $\mathrm{dE}=210 \mathrm{eV}$, for silver $\mathrm{dE}=430 \mathrm{eV}$ ) and below, called background image (for chloride $\mathrm{dE}=180 \mathrm{eV}$, for silver $\mathrm{dE}=345 \mathrm{eV}$ ). To control for the possibility of detecting false-positive signals due to local mass effects, in several cases, an indifferent element (calcium) was also assayed in electron-dense precipitates at the element- 


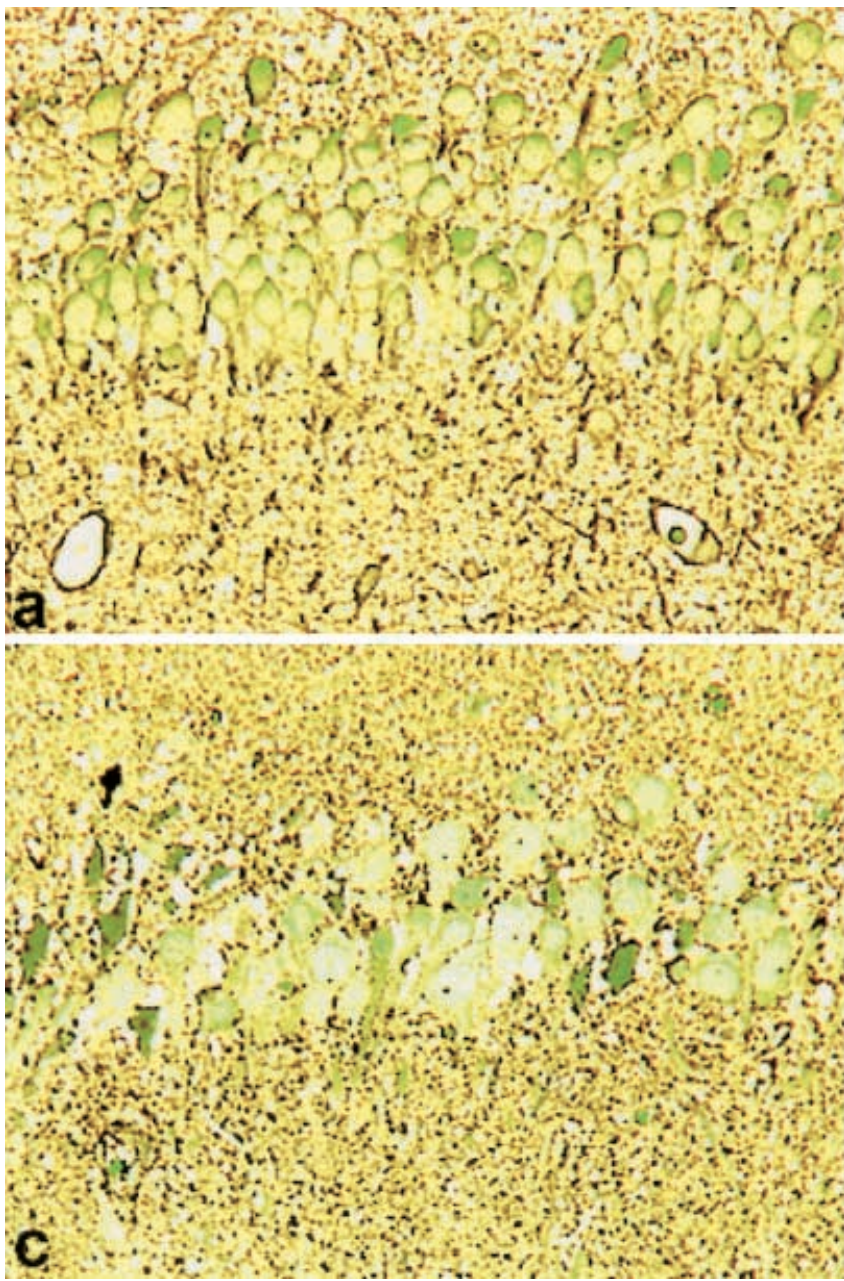

Fig. 1a-d Light microscopic demonstration of chloride distribution in the CA1 region of hippocampal slices with chloride trapping during freeze-substitution. a, b Principal cells from newborn hippocampus. c, d Pyramidal cells from adult animal. a, c Survey images. b, d Pyramidal cells imaged with higher magnification. Dark brown, dot-like reaction products are easily recognized at both magnifications. In the newborn rat the dark precipitates are more homogeneously distributed, and can be equally found over cytoplasmic and extracellular regions (a, b). Particularly, clustering of precipitates over the main apical dendrites can be recognized (b). In the adult animal the precipitates tend to accumulate outside the principal cells, consequently the main apical dendrites and the cell bodies appear faintly in the grainy background (c, d). Bar $30 \mu \mathrm{m}(\mathbf{a}, \mathbf{c}), 15 \mu \mathrm{m}(\mathbf{b}, \mathbf{d})$

specific ionization edge $(\mathrm{dE}=355 \mathrm{eV})$ and below $(\mathrm{dE}=310 \mathrm{eV})$. Images were collected at an instrumental magnification of $20,000-30,000 \times$ using $80 \mathrm{kV}$ accelerating voltage, an objective aperture of $90 \mu \mathrm{m}$, a spectrometer entrance aperture of $650 \mu \mathrm{m}$, and a slit aperture of 8-10 eV. Between 300 and 500 frames were collected and averaged to achieve a good signal/noise ratio for every image. Furthermore, a shading correction for uneven illumination was performed at each $\mathrm{dE}$ value using a defocused image as reference. The difference image (shading corrected "background" image subtracted from the similarly processed "edge" image) resulted in the net distribution pattern of the respective element. The final elemental distribution pattern was visualized at the confidence limit determined by the mean $+3 \times \mathrm{SD}$ rule: above this significance limit each image point was color-coded according to the actual significance level (starting from red at the mean $+3 \times$ SD

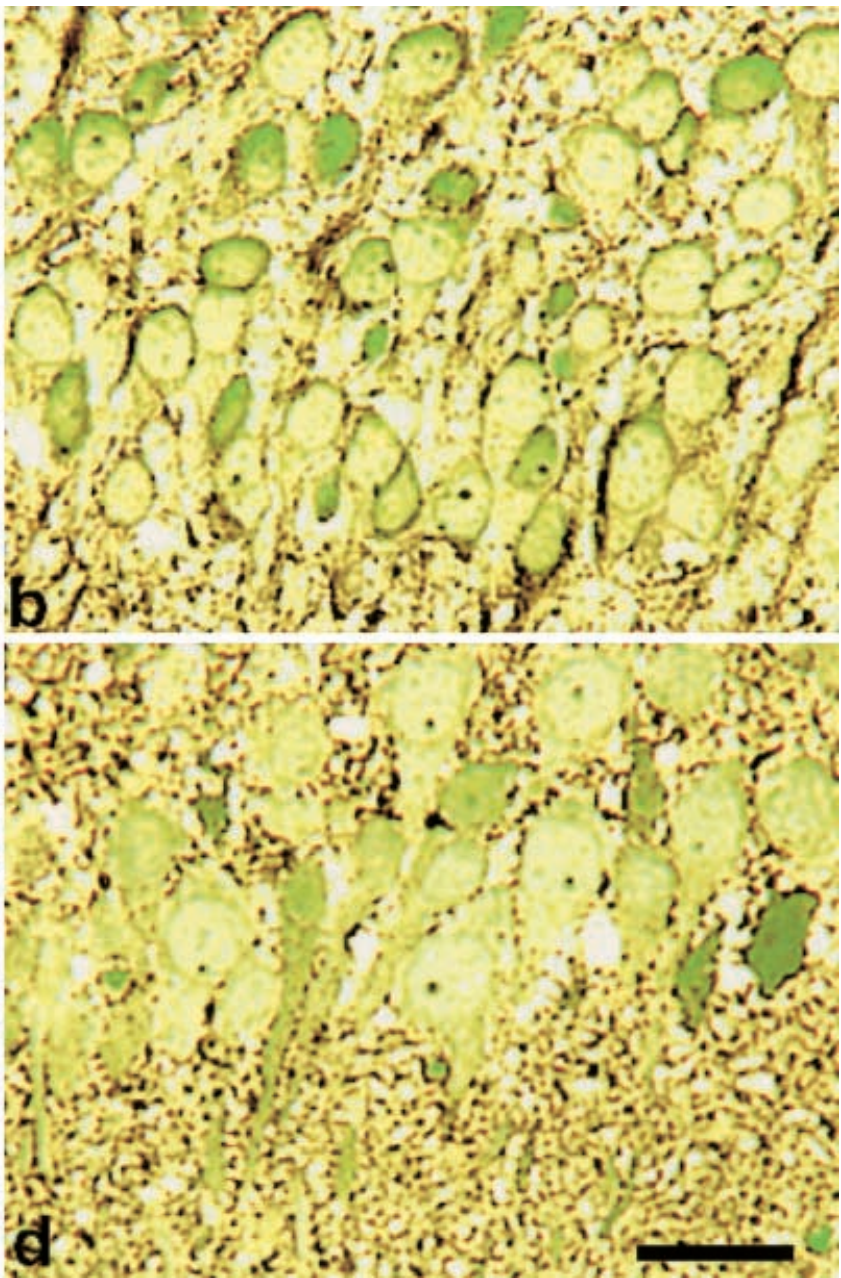

and reaching white at mean $+6 \times \mathrm{SD}$ ). Below the mean $+3 \times \mathrm{SD}$ level all pixels were deleted in the net distribution pattern. The color-coded elemental distribution images were then superimposed on the corresponding structural images, recorded, and inverted at $\mathrm{dE}=250 \mathrm{eV}$ to check for the correlation between the local arrangement of the precipitates, visible in the conventional transmission mode of the microscope, and the specific elemental contents.

\section{Electron energy loss spectroscopy (EELS)}

Sections used for ESI were utilized also for the EELS measurements. Spot analyses were performed on randomly selected electron-dense precipitates in order to complete the analytical characterization of the reaction products obtained with the ESI method. The electron microscopic parameters of such analyses were: $80 \mathrm{kV}$ accelerating voltage, $85,000 \times$ primary magnification, $0.42 \mu \mathrm{m}^{2}$ analyzed area, $300 \mu \mathrm{m}$ spectrometer entrance aperture, $90 \mu \mathrm{m}$ objective aperture, and $2 \mathrm{eV}$ slit width. All spectra were recorded with a photomultiplier tube installed into the photocamera chamber of the electron microscope. The recording ranges were $350-550 \mathrm{eV}$ for silver, $180-260 \mathrm{eV}$ for chloride, and $300-500 \mathrm{eV}$ for calcium. Dwell time was set to $3 \mathrm{~s}$ per channel of $0.5-2.0 \mathrm{eV}$. The spectrum recording and evaluation was performed with the EELS 1.3 program of the image analyzer. Background subtraction was performed after fitting a curve to points of the spectrum lying at the lower energy side of the questioned absorption edge and then the elements were identified by comparing the shape of the net curve with standard reference spectra (Reimer et al. 1992). 


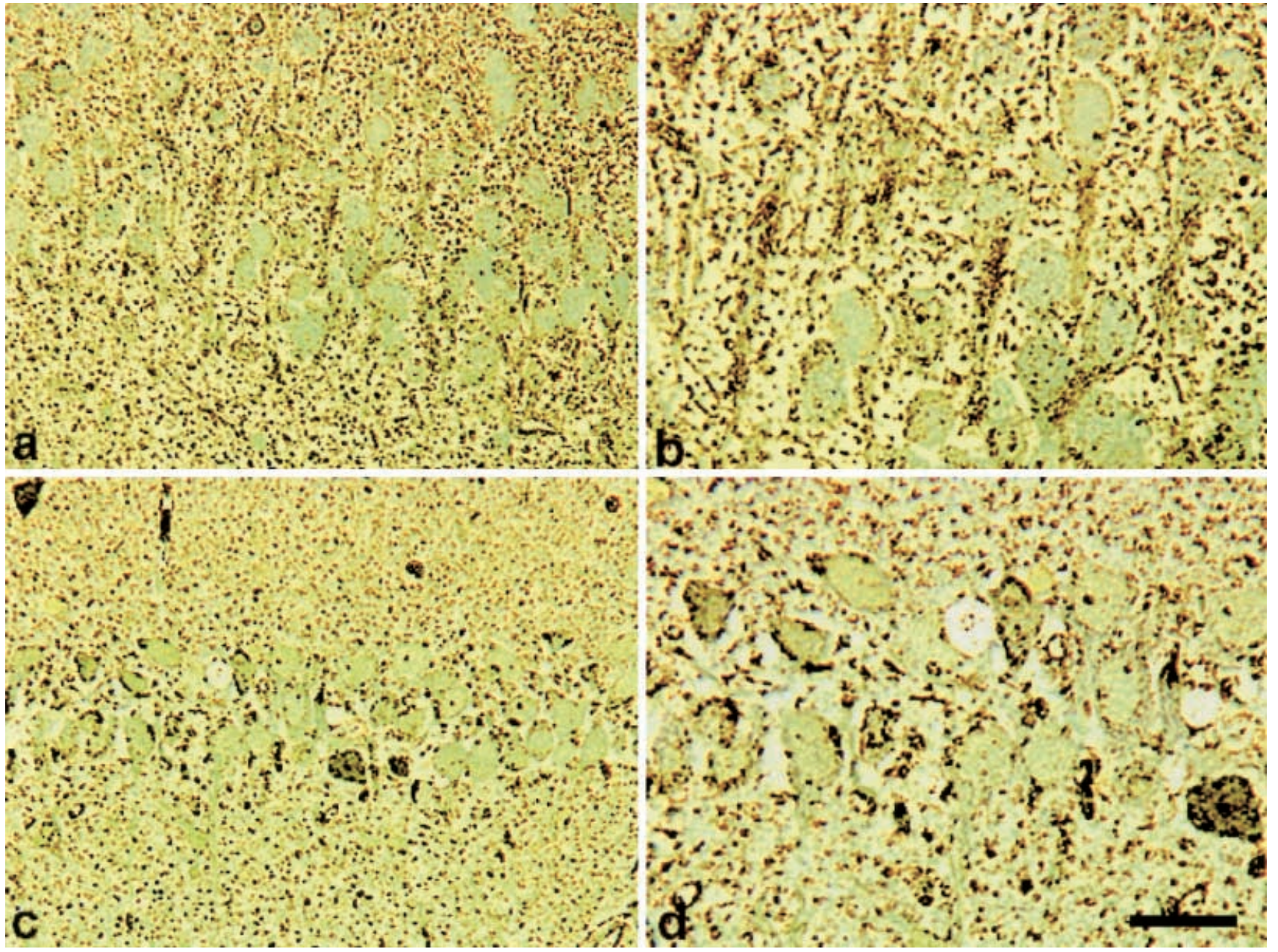

Fig. 2a-d Light microscopic demonstration of chloride distribution in the CA1 region of hippocampal slices with chloride trapping during aldehyde fixation. a, b Principal cells from newborn hippocampus. c, d Pyramidal cells from adult animal. a, c Survey images. b, d Pyramidal cells imaged with higher magnification. The dark punctate precipitates are similar to those obtained with freeze-substitution, although their number seems to be less as compared to Fig. 1. Due to the better preservation, tissue features are more easily recognizable with the aldehyde fixation technique: the main components of the cell bodies (nucleus, nucleolus, cytoplasm), as well as the main dendrites are better discernible from the background both in the newborn (a, b) and the adult hippocampus (c, d). The characteristics of the distribution of the precipitates, however, are comparable to the frozen material: in the newborn hippocampus precipitates are equally visible over the cytoplasm and the extracellular space (b), while in the adult rat the reaction products tend to delineate the cell bodies and the apical dendrites (d). Bar $30 \mu \mathrm{m}(\mathbf{a}, \mathbf{c})$, $15 \mu \mathrm{m}(\mathbf{b}, \mathbf{d})$

\section{Results}

Light microscopic demonstration of tissue chloride by silver trapping

Light microscopic visualization of chloride distribution in the nervous tissue was attempted by transforming tissue chloride to insoluble precipitates with silver ions either during physical (fast freezing followed by freezesubstitution) or chemical (aldehyde immersion) fixation. Both methods resulted in similar reaction products which, after further physical intensification, could be easily and unequivocally recognized under the light microscope (Figs. 1, 2). After counterstaining, the reaction products remained invariably visible while structural features became more apparent (Fig. 7).

For these attempts of chloride localization, transverse hippocampal slices were used where relevant structures could be observed close to the surface of the samples. The simultaneous investigation of large domains of slices was ensured by using single sections, which (after oriented embedding) were cut parallel to the surface of the slices. In such a way an optimal depth range could be easily found for the characterization of the chloride distribution, which was regularly not deeper than 30-35 $\mu \mathrm{m}$, and not closer than 10-15 $\mu \mathrm{m}$ to the surface. Too close to the surface numerous damaged structures (cell bodies, processes) could be found, due to the mechanical damage caused by the slice preparation. On the other hand, in the deeper layers, either the ice crystal formation made the structure inadequate for anatomical work (during freeze-substitution), or penetration problems of the silver ions were encountered (during the aldehyde fixation) resulting in lower number of pre- 

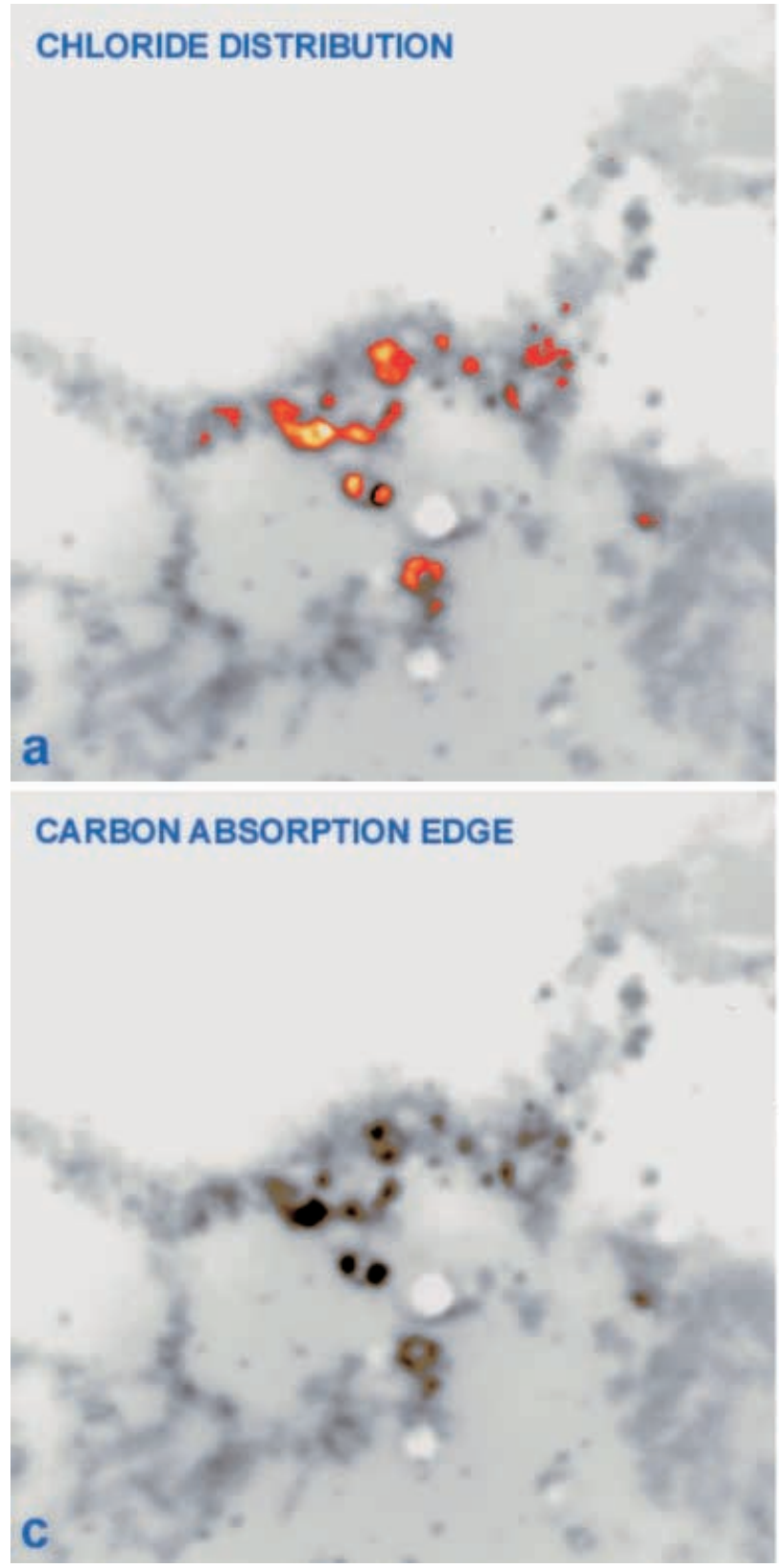

Fig. 3a-d Distribution of tissue silver and chloride after the histochemical reaction during freeze-substitution; electron spectroscopic imaging (ESI) analysis. Unstained ultrathin (thickness $<35 \mathrm{~nm}$ ) sections, obtained from an adult animal, were imaged at the carbon absorption edge $(\mathrm{dE}=250 \mathrm{eV})$ then inverted to yield an image resembling conventional bright-field pictures $(\mathbf{c})$. From the tissue mainly the membrane constituents can be recognized besides the electron-dense reaction products, which are confined between the membrane lamellae (c). The ESI analysis proved that significant silver and chloride signals were obtained only at the positions of the electron-dense precipitates (a, b). The distribution of the significant signal for both elements (color coded from red to yellow to white) coincides with each other, as well as with the distribution of the black precipitates themselves. Similar analysis of an indifferent element (calcium) of the same area yielded only nonsignificant background noise (d). Bar $0.2 \mu \mathrm{m}$

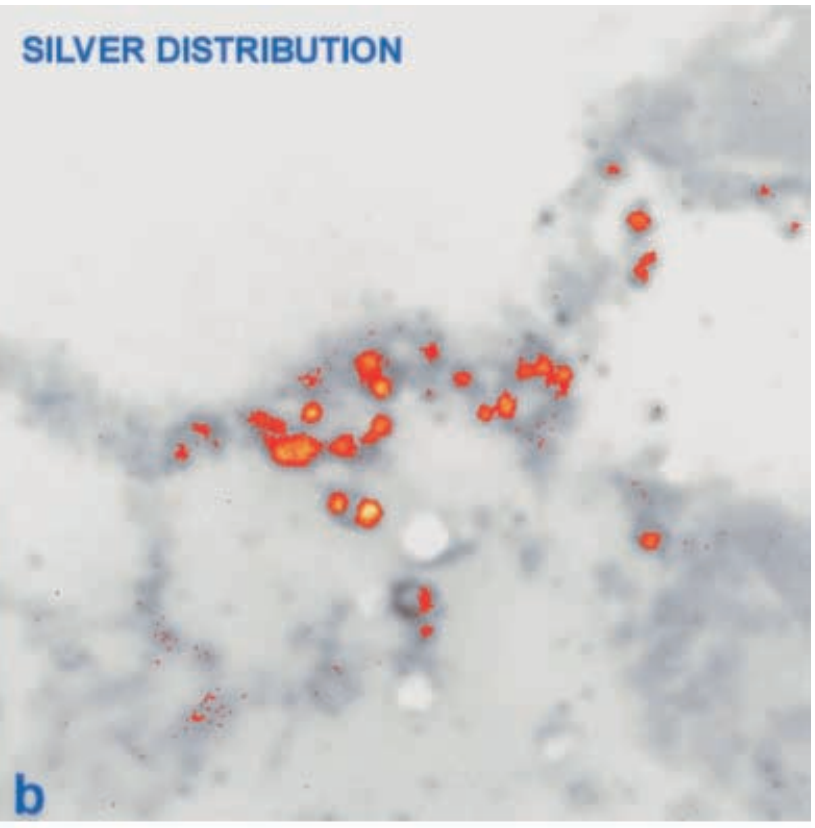

\section{CALCIUM DISTRIBUTION}

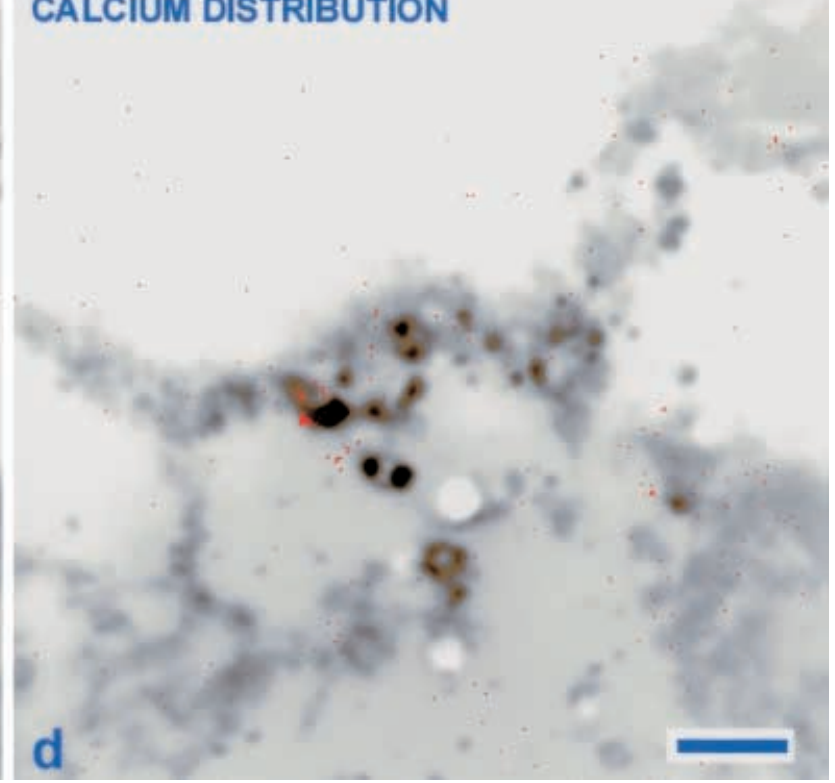

cipitates in deeper layers. Within the optimal range, however, the two methods yielded comparable distribution patterns (see, for example, Fig. 1b versus Fig. 2b and Fig. 1d versus Fig. 2d), though the number of deposits seemed to be somewhat less in aldehyde-fixed material.

The composition of the reaction products was determined by means of spot EELS analysis in the electron microscope, which revealed the presence of only silver and chloride in the precipitates. Since the twodimensional distribution analysis (ESI) proved that these constituents were present only in the precipitates, we concluded that the distribution of precipitates represented that of tissue chloride after the fixation (Figs. 3, 4, 5, 6). 

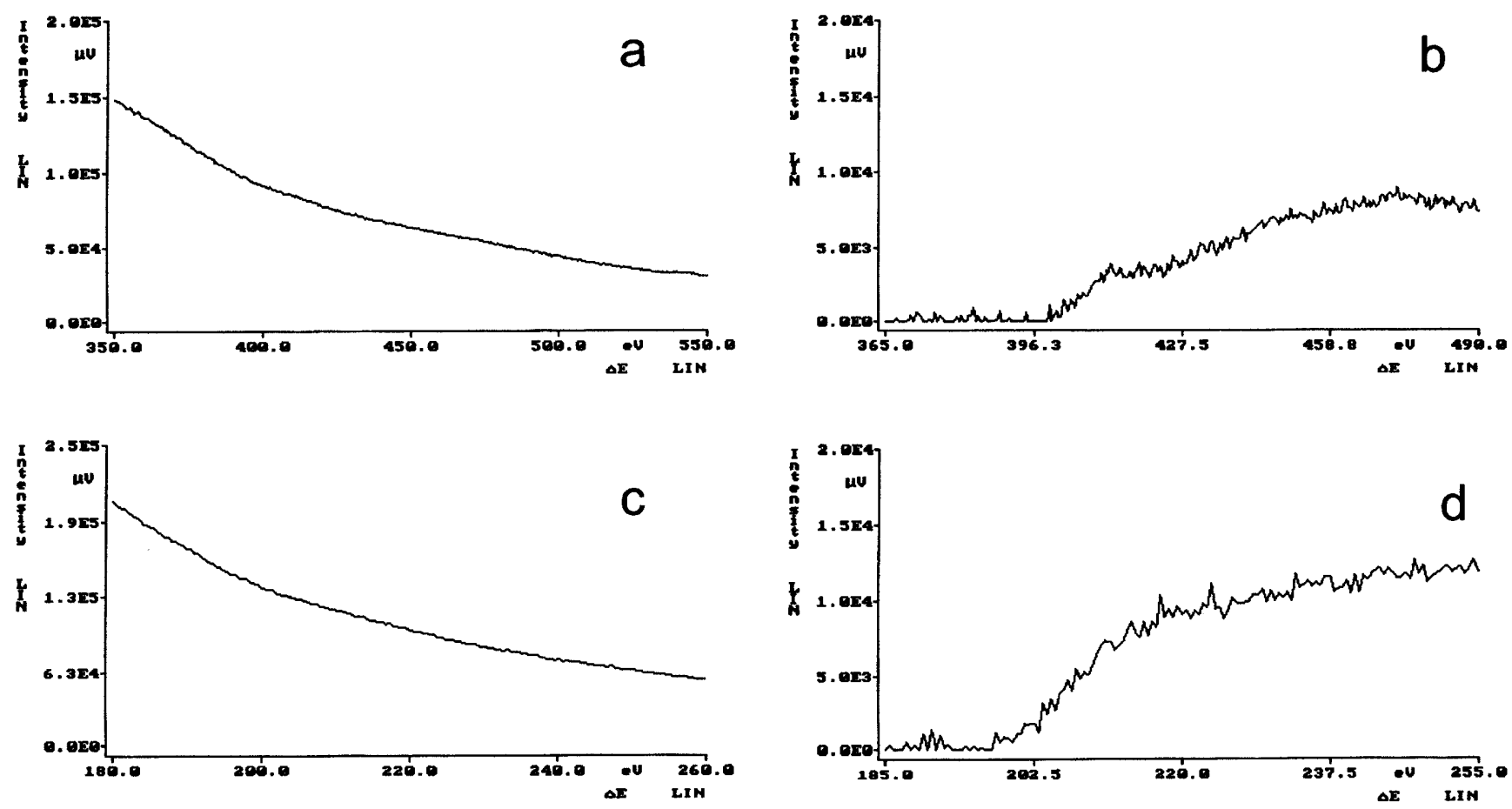

Fig. 4a-d Composition of electron-dense precipitates obtained with freeze-substitution; electron energy loss spectroscopy (EELS) analysis. Spectrum segments around the absorption edges of silver $(\mathbf{a}, \mathbf{b})$ and chloride $(\mathbf{c}, \mathbf{d})$ are shown before $(\mathbf{a}, \mathbf{c})$ and after $(\mathbf{b}, \mathbf{d})$ background subtraction. By comparison with standard curves the Cl- $\mathrm{L}_{2,3}\left(\Delta \mathrm{E}_{\text {ion }}=197.5 \mathrm{eV}\right)$ and the $\mathrm{Ag}-\mathrm{M}_{4,5}\left(\Delta \mathrm{E}_{\text {ion }}=370 \mathrm{eV}\right)$ absorption edges could be identified. With similar spot analysis no other elements were detected in the electron-dense precipitates

Function-dependent chloride distribution in hippocampal slices

To test the capability of the procedures described, we applied the chloride-trapping method to hippocampal slices in which, on the basis of literature data, different chloride distribution patterns should be expected (see, for example, Ben-Ari et al. 1989; Cherubini et al. 1990). We tried to find conditions when probably different steady-state distributions exist for a sufficiently long period, such that the duration of the fixation does not introduce a serious limitation. Thus, we decided to compare the chloride distribution in the CA1 region of newborn and adult hippocampi, as well as to detect changes induced by epileptiform activity.

In the newborn hippocampus we could detect numerous deposits over the cytoplasm of the CA1 pyramidal cells and in the extracellular space as well, both after freezesubstitution and aldehyde fixation (Figs. 1b, 2b). In the adult animals the majority of the precipitates was localized in the extracellular compartments (Figs. 1d, 2d) which indicates a higher gradient of chloride across the plasma membrane in the adult. Particularly, in the cytoplasm of adult CA1 pyramidal cells in aldehyde-fixed material we could hardly detect single deposits (Fig. 2d). This might correspond to the observation that generally

lower numbers of precipitates were encountered after aldehyde fixation in comparison to the freeze-substituted material.

Although visually there seems to be a striking difference between the precipitate density over the pyramidal cells bodies of newborn and adult animals with both preparation methods (Figs. 1, 2), we also estimated the relative amount of precipitates numerically. For this purpose we selected five or six pyramidal cells from each of four groups (newborn and adult animals with freeze-substitution, as well as newborn and adult animals with aldehyde fixation) and determined the relative area of the precipitates in relation to the corresponding cytoplasmic area. The comparison of the proportion of the area covered by the precipitates to the full cytoplasmic area of newborn and adult pyramidal cells yielded significant differences both with freeze substitution [newborn: $10.04 \pm 1.56(\mathrm{SEM}) \times 10^{-2}$, adult: $2.36 \pm 1.47(\mathrm{SEM}) \times 10^{-2}$; $P<0.02$ ] and aldehyde fixation [newborn: 6.95 \pm 1.61 $(\mathrm{SEM}) \times 10^{-2}$, adult: $\left.0.32 \pm 0.14(\mathrm{SEM}) \times 10^{-2} ; P<0.01\right]$.

In the other experiment (4-aminopyridine model of epilepsy) we applied only the freeze-substitution technique to demonstrate the chloride distribution during epileptiform activity. The chloride distribution pattern obtained in the CA1 region of the epileptic hippocampus closely resembled that of the newborn hippocampus, indicating a reduced, or reversed transmembrane chloride gradient under this condition (Fig. 7).

\section{Discussion}

We tested the applicability of histochemical methods to gain information about function-related chloride distributions in neuronal structures. The silver-trapping procedure 

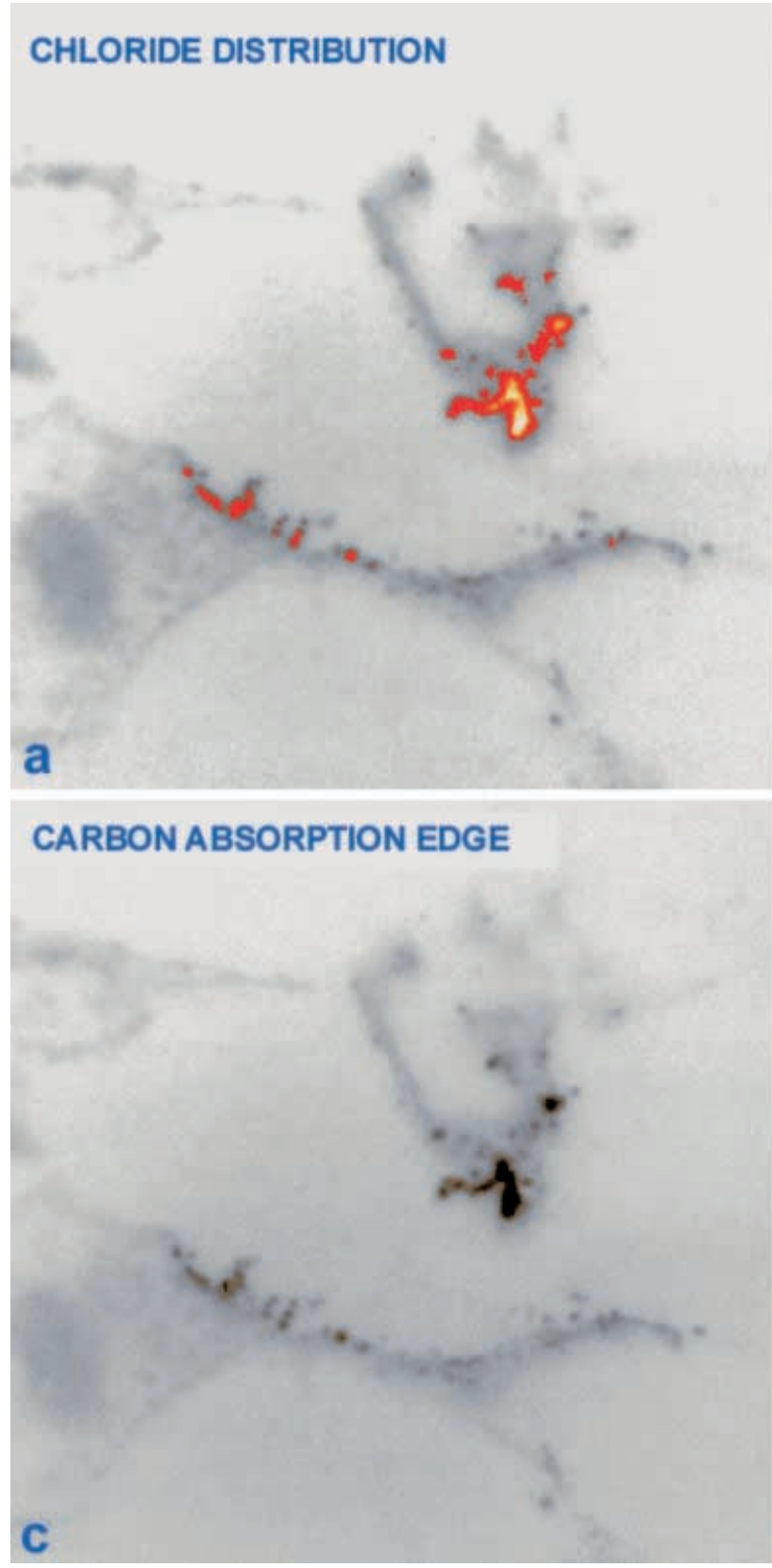

Fig. 5a-d Distribution of tissue silver and chloride after the histochemical reaction during aldehyde fixation; ESI analysis. Similar to the freeze-substituted material, unstained ultrathin (thickness $<35 \mathrm{~nm}$ ) sections, obtained from an adult animal, were imaged at the carbon absorption edge $(\mathrm{dE}=250 \mathrm{eV})$ and then inverted to yield an image resembling conventional bright-field pictures (c). From faint to dark gray-colored membrane segments can be recognized with electron-dense reaction products intermingled (c). The ESI analysis revealed significant silver and chloride signals only at the positions of the electron-dense precipitates $(\mathbf{a}, \mathbf{b})$, The distribution of both elements (color coded from red to yellow to white) coincides with each other, as well as with the pattern of the black precipitates. Similar analysis of calcium distribution of the same area yielded only non-significant background noise (d). Bar $0.2 \mu \mathrm{m}$

\section{SILVER DISTRIBUTION}

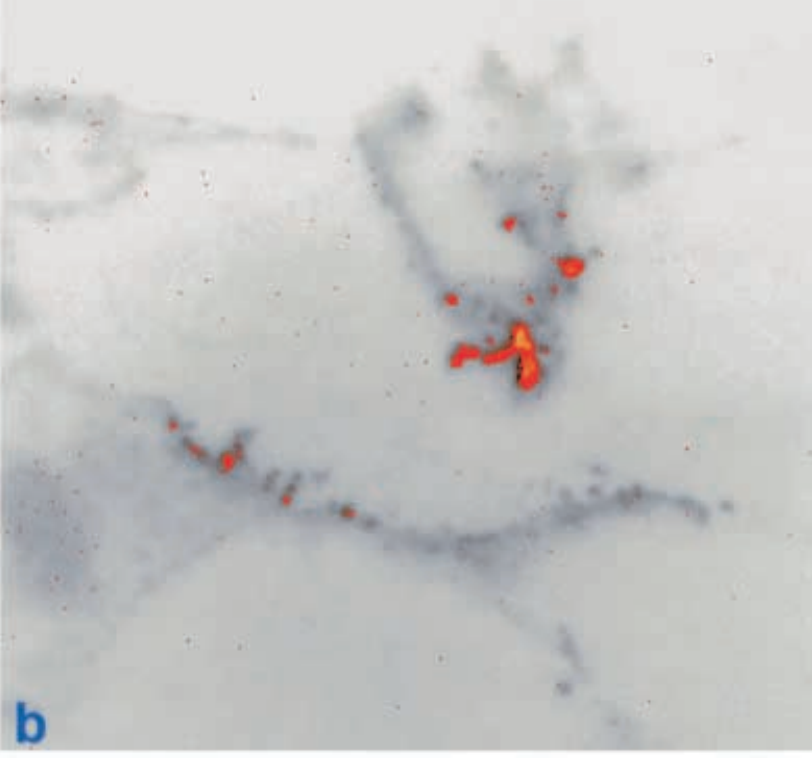

\section{CALCIUM DISTRIBUTION}

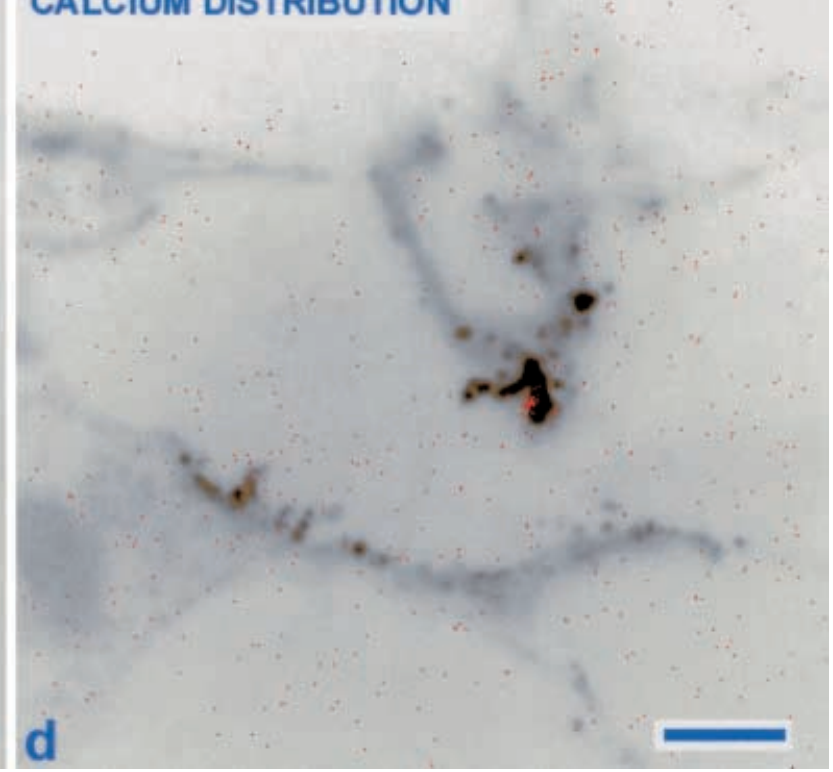

resulted in uniform reaction products both with freezesubstitution and aldehyde fixation. After silver intensification, the reaction products were light microscopically visible and their positions could be associated with identified tissue compartments. Both freeze-substitution and aldehyde fixation methods made possible the qualitative description of the chloride distribution in tissue layers close to the surface of the specimen.

\section{Limitations of the chloride-trapping technique}

Silver precipitation of chloride ions during freeze-substitution has already been used to demonstrate tissue chloride distributions both on light and electron microscopic scales (Van Harreveld 1966). While adapting the technique 

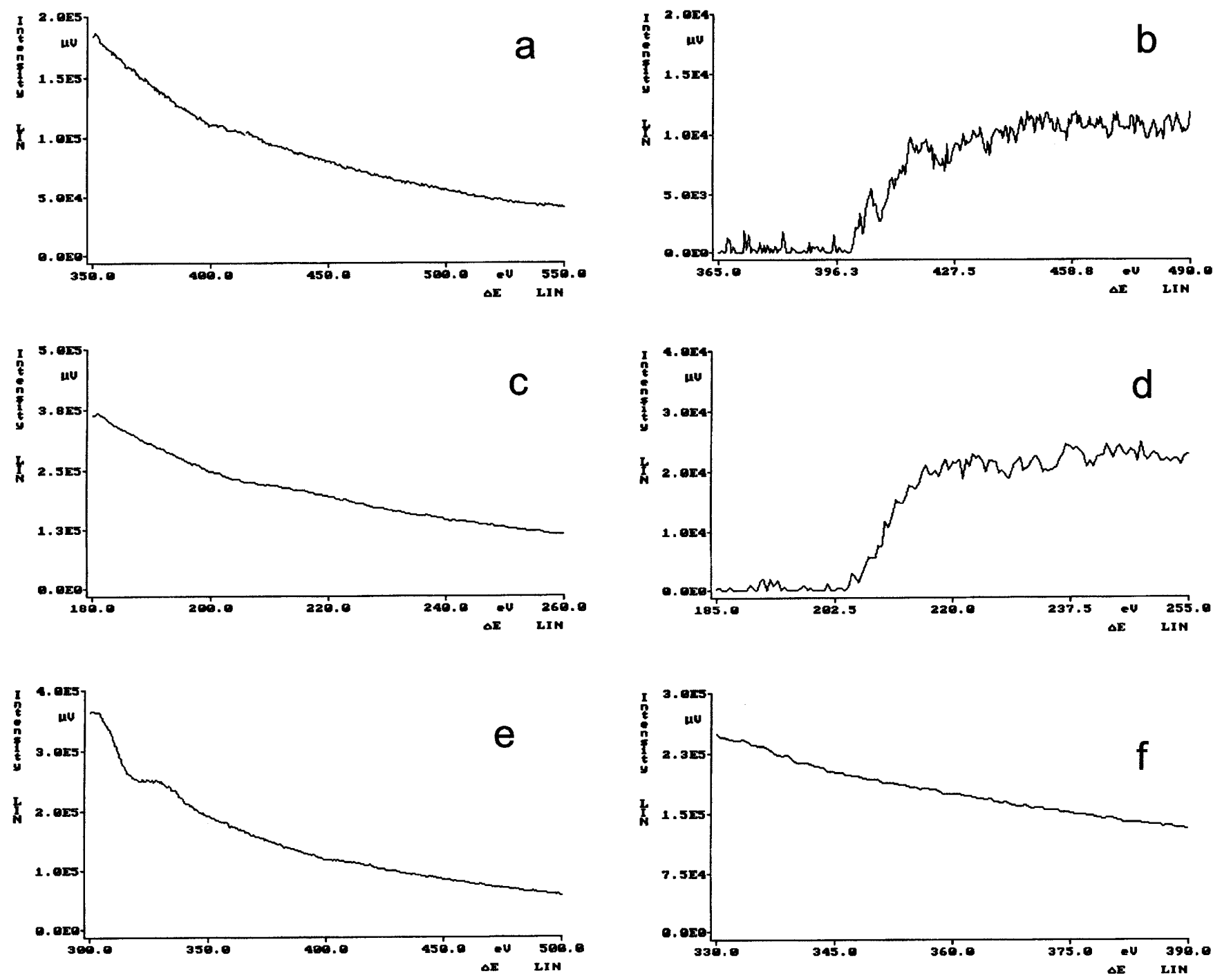

Fig. 6a-f Composition of electron-dense precipitates obtained with the aldehyde fixation technique; EELS analysis. Spectrum segments around the absorption edges of silver $(\mathbf{a}, \mathbf{b})$, chloride $(\mathbf{c}, \mathbf{d})$, and calcium $(\mathbf{e}, \mathbf{f})$ are shown before $(\mathbf{a}, \mathbf{c}, \mathbf{e})$ and after $(\mathbf{b}, \mathbf{d}, \mathbf{f})$ background subtraction. By comparison with standard curves the Cl- $\mathrm{L}_{2,3}\left(\Delta \mathrm{E}_{\text {ion }}=197.5 \mathrm{eV}\right)$ and the $\mathrm{Ag}-\mathrm{M}_{4,5}\left(\Delta \mathrm{E}_{\text {ion }}=370 \mathrm{eV}\right)$ absorption edges could be identified. With similar spot analysis neither calcium $(\mathbf{e}, \mathbf{f})$, nor other elements (not shown) were detected in the electron-dense precipitates

to hippocampal slices, method-related generic and tissuespecific problems were equally encountered. Adequate fixation of tissue morphology and the simultaneous preservation of the elemental composition/distribution require cooling of the tissue at extra high speed. The cooling speed, however, is limited by the low heat conductance of biological tissue. The development of the artifacts can be reduced by lowering the temperature of the cooling material, by using thin samples, and/or by smashing the tissue with metal mirrors cooled by low temperature fluids (for example, liquid nitrogen). This latter technique has been successfully applied to the

olfactory bulb of adult rats, where the characterization of the periglomerular cells was intended, since even with this crude technique the glomeruli remained intact and recognizable (Siklós et al. 1995). The same procedure, however, could be applied neither to intact hippocampi nor to hippocampal slice preparations. By pressing intact hippocampi to cooled metal surfaces the different principal layers became intermixed and the original position of the cells could not be determined. While the same technique with hippocampal slices did not cause such tissue dislocations, the slices usually broke to small pieces, which made the anatomical evaluation impossible. Since we could not improve the method by reducing the pressure applied to the metal mirrors even to negligible levels, we turned to the submerging technique for fast cooling of the tissue.

To improve tissue preservation during quenching of the tissue, several precautions have been taken. First, to avoid heat-insulating bubble formation during freezing, tissue was immersed into isopentane, cooled close to its melting point with liquid nitrogen. Secondly, to keep the conformation of slices intact they were bracketed 


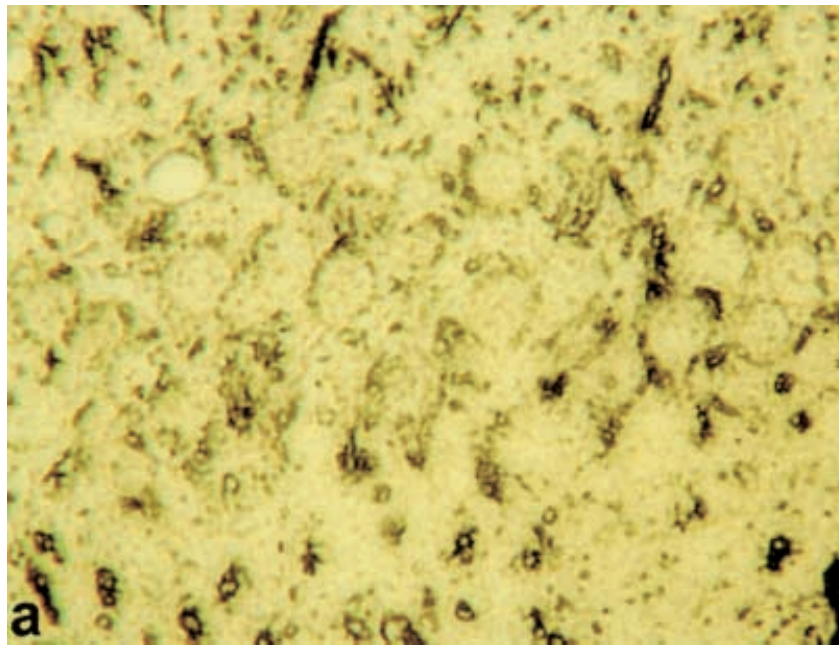

Fig. 7a, b Altered distribution of tissue chloride in 4-aminopyridinetreated slices. Pyramidal cells of the CA1 region of an adult hippocampus is shown, obtained with chloride trapping during freeze-substitution, before (a) and after (b) counterstaining to improve the structural identification. Evidently, the counterstaining does not change the distribution of the reaction products. a, b Tissue region comparable to Fig. 1d, which demonstrates the normal chloride distribution obtained with the same fixation method. Unlike in the normal slice, epileptiform activity results in large clusters of precipitates over the perikarya particularly in the cytoplasm around the nucleus, which is more clearly discernible after counterstaining (b). At the same time, the number of extracellular deposits seems to be reduced compared to the control situation, shown in Fig. 1d

between a pair of nylon sieves spaced just at the thickness of hippocampal slices. This sandwich construction could also be used for handling the tissue even without touching its surface. Finally, to reduce the heat capacity of the sandwich structure, large-holed sieves made from very thin fibers were selected, which were mounted to thin Teflon rings of large diameter $(5 \mathrm{~cm})$. Thus, at the vicinity of the slices, placed at the center of the sieves, only negligible supporting material was present which could act as an undesirable heat sink.

Despite all the feasible precautions, freezing of biological tissue is unavoidably accompanied by artifacts due to formation of ice crystals. The lower the cooling rate the larger the size of ice crystals formed. Since the cooling speed within the tissue during freezing is limited by the low heat conductance of the tissue, ice crystals of bigger size develop with increasing distance from the surface of the sample. Since these crystals destroy the structure proportionally to their size, depending on the aimed resolution and the intended quality of the tissue characterization there is only a narrow range close to the surface for the microscopic work (Zierold 1982, 1991).

To overcome the freezing artifacts, alternatively, chemical fixation of the tissue was also tested using the fixative as the vehicle of the trapping agent, which was silver in our case. A similar procedure has already been successfully applied to demonstrate tissue calcium at the electron microscope (Borgers et al 1977, 1981). Since all conventionally used buffers resulted in immediate precipi-

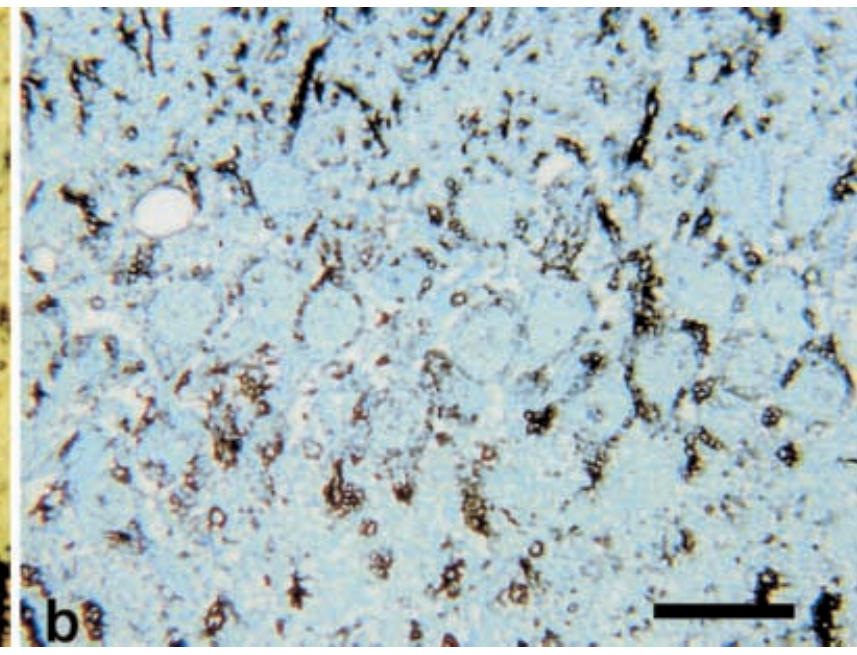

tation of silver in the solution, unbuffered fixative was used resulting in a final $\mathrm{pH}$ of 5.0-5.5. Despite such an acidic $\mathrm{pH}$, good tissue preservation could be achieved, however, we experienced a reduced penetration of silver into the deeper tissue layers. On the other hand, in the superficial 30- to 35- $\mu \mathrm{m}$-thick layer, the main features of the distribution of the precipitates were similar to those obtained with freeze-substitution, though a somewhat lower number of deposits was regularly seen.

Specificity of the histochemical reaction

The overall quality of the tissue preservation did not allow high precision anatomical investigations on the ultrastructural level mainly due to the combined adverse effects of the surface damage of tissue slices during preparation and the development of freezing artifacts or the impaired penetration of silver during aldehyde fixation. Since, however, the histochemical reaction products could be identified reliably in the electron microscope and, furthermore, their anatomical relation to main cellular compartments could be determined, microanalytical assay of their composition was carried out. To reduce the artifacts due to multiple electron scattering within the sample and the disturbing effects of additional elemental constituents, unstained ultrathin $(25-35 \mathrm{~nm})$ sections were used. With such sections very faint microscopic images were obtained, which could be studied only at the carbon absorption edge after video enhancement of the image, and usually after exercise sessions to learn the characteristics of the structure. With the combination of the ESI (Figs. 3, 5) and the spot EELS analysis of the precipitates (Figs. 4, 6) we could conclude that: (1) the detectable relevant constituents of the precipitates are silver and chloride, and that (2) these elements can be detected only in the reaction products. Thus, the distribution of the precipitates visible with conventional microscopic methods can be accepted as a representation of the chloride distribution in the tissue after fixation.

Although the analytical characterization of the silvertrapping method on a microscopic scale could be carried 
out, we could not directly determine its overall chloride retention efficiency. This type of control would have required an independent (for example, atomic absorption spectroscopic; AAS) determination of the chloride content of the intact tissue (before the histochemical reaction) and comparison to the chloride concentration after the reaction finished. Besides the general difficulties of determining anion concentrations with AAS (Price 1977), the main problem arose from the methodological similarity of our method and the chloride determination procedure with analytical atomic absorption: the chloride determination with AAS is indirect, and also based on silver precipitation. However, two indirect arguments can be raised in favor of a high chloride retention efficiency of the methods described:

1. During freeze-substitution, since the substitution front is always saturated with silver ions, the tissue chloride is trapped, without loss, immediately as the substitution front advances, supposing that the substitution time is long enough for the entire volume of the sample to be substituted. Since we could not find changes in the pattern of the precipitates by increasing the substitution time, this latter assumption might have been valid.

2. Similar distribution pattern could be obtained with the chemical fixation technique, working with different tissue-solution interactions. We think, that the observed lower number of precipitates after aldehyde fixation was not due to an overall insufficient concentration of silver ions in the solution. In several experiments, an up to five- and tenfold increase of the amount of silver in the fixative neither caused a change in the pattern nor in the amount of the reaction products in the upper layers of the slices. Instead, we think, that due to the limited diffusion speed, a longer time is needed for the silver ions to reach the central parts of the sample. Since the comparison of the methods restricted to the surface layers of the sample yielded similar distribution patterns, we have not tried to extend the fixation time with the aldehyde fixation technique. On the other hand, due to the lower penetration speed of silver ions compared to the aldehyde, besides a certain loss, chloride redistribution within the tissue can also be expected during the time of fixation. It is feasible to think that this shortage of the method is the smallest in that narrow range just below the surface of the slices where the penetration is facilitated by the spongiform structure of the slices in this area.

\section{Significance of the revealed chloride distributions}

By comparing the chloride distribution in the CA1 region of newborn and adult hippocampal slices (Figs. 1,2) we could arrive at a conclusion which paralleled those physiological results which demonstrated that the shift from excitatory to inhibitory effects of GABA was accompanied by a change in the transmembrane chloride distribution. The direction of this change, from the reduced gradient in the newborn to a steeper gradient in the adult, emphasizes the role of $\mathrm{Cl}^{-}$in shaping postsynaptic consequences of the released GABA, and might provide additional direct $d$ ata for the interpretation of the ionic basis of the actual GABA effect.

In another test of the capacity of the chloride-trapping procedure during freeze-substitution we could demonstrate an altered $\mathrm{Cl}^{-}$gradient in hippocampal CA1 pyramidal cells following epileptiform activity which further accentuates the role of the $\mathrm{Cl}^{-}$gradient across the plasma membrane in the actual effect of GABA. This finding is in accord with reports on loss of GABAmediated inhibition during status epilepticus (Kapur and Coulter 1995), with the notion of reduced inhibition during epileptiform activity in vitro (Dingledine and Gjerstad 1980), as well as with clinical observations of reduced efficacy of benzodiazepines in the treatment of enduring partial status epilepticus (Treiman 1990). On the other hand, there have been reports on operative GABAergic inhibition during experimental epilepsy, thus the exact role of the chloride gradient under epileptic conditions is still questionable (Esclapez et al. 1997; Prince et al. 1997).

Although the method based on trapping of chloride ions either during freeze-substitution (or aldehyde fixation) is only qualitative, it is able to reveal minute changes in the chloride distribution in the nervous system. Due to our incomplete knowledge of subcellular events underlying epileptic activity, future studies are still warranted to study the ionic mechanisms underlying excitatory versus inhibitory effects of GABA. These experiments, if they can be designed to induce long-lasting changes preferably in in vitro preparations, might be supplemented with the presented methods to correlate physiological data with the light microscopic description of the chloride distribution in the same sample.

Acknowledgements This work was supported by grants from the Hungarian Scientific Research Fund (OTKA, T 017728), the Hungarian Academy of Sciences (AKP 97-8 3,2), and the Volkswagen Stiftung.

\section{References}

Alvarez-Leefmans $\mathrm{FJ}$ (1990) Intracellular $\mathrm{Cl}^{-}$regulation and synaptic inhibition in vertebrate and invertebrate neurons. In: Alvarez-Leefmans FJ, Russell JM (eds) Chloride channels and carriers in nerve, muscle, and glial cells. Plenum Press, New York, pp 109-158

Anderson WW, Lewis DV, Swartzwelder HS, Wilson WA (1986) Magnesium-free medium activates seizure-like events in the rat hippocampal slice. Brain Res 398:215-219

Avoli M, Barbarosie M, Lücke A, Nagao T, Lopantsev V, Köhling R (1996) Synchronous GABA-mediated potentials and epileptiform discharges in the rat limbic system in vitro. J Neurosci $16: 3912-3924$

Bauer R (1988) Electron spectroscopic imaging: an advanced technique for imaging and analysis in transmission electron microscopy. Methods Microbiol 20:113-146

Ben-Ari Y, Cherubini E (1991) Zinc and GABA in developing brain. Nature 353:220 
Ben-Ari Y, Cherubini E, Corradetti R, Gaiarsa JL (1989) Giant synaptic potentials in immature rat CA3 hippocampal neurones. J Physiol 416:303-325

Bloom FE, Iversen LL (1971) Localizing ${ }^{3} \mathrm{H}-\mathrm{GABA}$ in nerve terminals of rat cerebral cortex by electron microscopic autoradiography. Nature 229:628-630

Borgers M, De Brabander DM, Van Reempts DJ, Awouters F, Jacob WA (1977) Intranuclear microtubules in lung mast cells of guinea pigs in anaphylactic shock. Lab Invest $37: 1-8$

Borgers M, Thoné F, Van Neuten JM (1981) The subcellular distribution of calcium and the effects of calcium-antagonists as evaluated with a combined oxalate-pyroantimonate technique. Acta Histochem S24:327-332

Bormann J, Hamill OP, Sakmann B (1987) Mechanisms of anion penetration through channels gated by glycine and gammaaminobutyric acid in mouse cultured spinal neurones. J Physiol 385:243-286

Cala PM (1990) Principles of cell volume regulation. Ion flux pathways and roles of anions. In: Alvarez-Leefmans FJ, Russell JM (eds) Chloride channels and carriers in nerve, muscle, and glial cells. Plenum Press, New York, pp 67-83

Cherubini E, Rovira C, Gaiarsa JL, Corradetti R, Ben-Ari Y (1990) GABA-mediated excitation in immature rat CA3 hippocampal neurons. Int J Dev Neurosci 8:481-490

Cherubini E, Gaiarsa JL, Ben-Ari Y (1991) GABA: an excitatory transmitter in early postnatal life. Trends Neurosci 14:515-519

Dingledine R, Gjerstad L (1980) Reduced inhibition during epileptiform activity in the in vitro hippocampal slice. J Physiol 305:297-313

Esclapez M, Hirsch JC, Khazipov R, Ben-Ari Y, Bernard C (1997) Operative GABAergic inhibition in hippocampal CA1 pyramidal neurons in experimental epilepsy. Proc Natl Acad Sci USA 94:12151-12156

Hara M, Inoue M, Yasukura T, Ohnishi S, Mikami Y, Inagaki C (1992) Uneven distribution of intracellular $\mathrm{Cl}^{-}$in rat hippocampal neurons. Neurosci Lett 143:135-138

Horton RW (1991) GABA dysfunction in animal models of epilepsy. In: Tunnicliff G, Raess BU (eds) GABA mechanisms of epilepsy. Wiley-Liss, New York, pp 121-147

Inoue M, Hara M, Zeng XT, Hirose T, Ohnishi S, Yasukura T, Uriu T, Omori K, Minato A, Inagaki C (1991) An ATP-driven $\mathrm{Cl}^{-}$pump regulates $\mathrm{Cl}^{-}$concentrations in rat hippocampal neurons. Neurosci Lett 134:75-78

Kapur J, Coulter DA (1995) Experimental status epilepticus alters $\gamma$-aminobutyric acid type A receptor function in CA1 pyramidal neurons. Ann Neurol 38:893-900

Krnjevic K (1991) Significance of GABA in brain function. In: Tunnicliff G, Raess BU (eds) GABA mechanisms of epilepsy, Wiley-Liss, New York, pp 47-87

Kyrozis A, Reichling DB (1995) Perforated-patch recording with gramicidin avoids artifactual changes in intracellular chloride concentration. J Neurosci Methods 57:27-35

Macdonald RL, Olsen RW (1994) $\mathrm{GABA}_{\mathrm{A}}$ receptor channels. Annu Rev Neurosci 17:569-602

Maxwell MH (1978) Two rapid simple methods used for the removal of resins from $1.0 \mu \mathrm{m}$ thick epoxy section. J Microsc 112:253-255

Mehta AK, Ticku MK (1999) An update on GABA $_{A}$ receptors. Brain Res Rev 29:196-217

Michelson HB, Wong KS (1991) Excitatory synaptic responses mediated by $\mathrm{GABA}_{\mathrm{A}}$ receptors in the hippocampus. Science 253:1420-1423

Mody I, Otis TS, Staley KJ, Köhr G (1992) The balance between excitation and inhibition in dentate granule cells and its role in epilepsy. In: Engel JJ, Wasterlain C, Cavalheiro EA, Heinemann U, Avanzini G (eds) Molecular neurobiology of epilepsy (epilepsy res suppl 9). Elsevier Science Publishers, Amsterdam, pp 331-339
Mody I, De Koninck Y, Otis TS, Soltesz I (1994) Bridging the cleft at GABA synapses in the brain. Trends Neurosci 17: $517-525$

Obata K (1976) Excitatory effects of GABA. In: Roberts E, Chase TN, Tower DB (eds) GABA in nervous system function, Raven Press, New York, pp 283-286

Owens DF, Boyce LH, Davis MBE, Kriegstein AR (1996) Excitatory GABA responses in embryonic and neonatal cortical slices demonstrated by gramicidin perforated-patch recordings and calcium imaging. J Neurosci 15:6414-6423

Perreault P, Avoli M (1991) Physiology and pharmacology of epileptiform activity induced by 4-aminopyridine in rat hippocampal slices. J Neurophysiol 65:771-785

Price WJ (1977) Analytical atomic absorption spectrometry. Heyden, London

Prince DA, Jacobs KM, Salin PA, Hoffman S, Parada I (1997) Chronic focal neocortical epileptogenesis: does disinhibition play a role? Can J Physiol Pharmacol 75:500-507

Reimer L, Zepke U, Moesch J, Schulze-Hillert ST, Ross-Messemer M, Probst W, Weimer E (1992) EELS spectroscopy. A reference handbook of standard data for identification and interpretation of electron energy loss spectra and for generation of electron spectroscopic images. Zeiss, Electron Optics Division, Oberkochen

Richardson KC, Jarett L, Finke EH (1960) Embedding in epoxy resins for ultrathin sectioning in electron microscopy. Stain Technol 35:313-323

Rivera C, Voipio J, Payne JA, Ruusuvuori E, Lahtinen H, Lamsa K, Pirvola U, Saarma M, Kaila K (1999) The $\mathrm{K}^{+} \mathrm{Cl}^{-}$co-transporter KCC2 renders GABA hyperpolarizing during neuronal maturation. Nature 397:251-255

Sigel E, Baur R, Trube G, Möhler H, Malherbe P (1990) The effect of subunit composition of rat brain $\mathrm{GABA}_{\mathrm{A}}$ receptors on channel function. Neuron 5:703-711

Siklós L, Rickmann M, Joó F, FreemanWJ, Wolff JR (1995) Chloride is preferentially accumulated in a subpopulation of dendrites and periglomerular cells of the main olfactory bulb in adult rats. Neuroscience 64:165-172

Sloviter RS (1987) Decreased hippocampal inhibition and a selective loss of interneurons in experimental epilepsy. Science 235:73-76

Spurr AR (1969) A low viscosity epoxy resin embedding medium for electron microscopy. J Ultrastruct Res 26:31-43

Szente M, Baranyi A (1987) Mechanism of aminopyridineinduced ictal seizure activity in the cat neocortex. Brain Res 413:368-373

Thompson SM (1989) Mechanisms underlying the lability of GABAergic inhibition in the hippocampus. In: Chan-Palay V, Köhler C (eds) The hippocampus. New vistas. Liss, New York, pp 225-236

Thompson SM (1994) Modulation of inhibitory synaptic transmission in the hippocampus. Prog Neurobiol 42:575-609

Treiman DM (1990) The role of benzodiazepines in the management of status epilepticus. Neurology 40:32-42

Van Harreveld A (1966) Brain tissue electrolytes. Butterworts, London

Verdoorn TA, Draguhn A, Ymer S, Seeburg PH, Sakmann B (1990) Functional properties of recombinant rat $\mathrm{GABA}_{\mathrm{A}}$ receptors depend upon subunit composition. Neuron 4:919-928

Verkman AS (1990) Development and biological application of chloride-sensitive fluorescent indicators. Am J Physiol 259: C375-C388

Zhang SJ, Jackson MB (1993) GABA-activated chloride channels in secretory nerve endings. Science 259:531-534

Zierold K (1982) Cryopreparation of mammalian tissue for X-ray microanalysis in STEM. J Microsc 125:149-156

Zierold K (1991) Cryofixation methods for ion localization in cells by electron probe microanalysis. A review. J Microsc 161:357-366 